\title{
María Luz Morales y su labor en la editorial Araluce*
}

\section{María Luz Morales and Her Work at Araluce Publishing House}

\author{
Teresa Julio \\ Universidad de Vic - UCC \\ tjulio@uvic.cat \\ ORCID iD: https://orcid.org/0000-0003-2966-9288
}

\section{RESUMEN}

En el presente artículo se analiza el trabajo de la periodista, escritora, adaptadora y traductora María Luz Morales para la editorial Araluce, empresa barcelonesa impulsada por Ramón de S. N. Araluce a finales del siglo XIX y principios del XX. Se aporta nueva documentación acerca de Araluce y Morales, y se presta especial atención a las colecciones infantiles y juveniles en las que colaboró, enmarcándolas en el contexto histórico-político en que nacieron y se desarrollaron.

Palabras Clave: editorial Araluce; Ramón de S. N. Araluce; María Luz Morales; literatura infantil y juvenil.

\section{ABSTRACT}

This article analyses the work of the journalist, writer, adaptor and translator María Luz Morales for Araluce publishing house, a Barcelona firm run by Ramón de S. N. Araluce in the late nineteenth and early twentieth centuries. New documents are brought to light in connection with Araluce and Morales, with particular attention to her contributions to children's and young adult series in the framework of the historical and political context in which they emerged and developed.

Key words: Araluce publishing house; Ramón de S. N. Araluce; María Luz Morales; Children's and young adult literature.

* Este trabajo se inscribe en las actividades del Grupo de Estudios de Género: Traducción, Literatura, Historia y Comunicación (GETLIHC) (2017, SGR 136) de la Universitat de Vic-Universitat Central de Catalunya y en el proyecto $\mathrm{I}+\mathrm{D}+\mathrm{i}$ «Traducción y censura: género e ideología (1939-2000)», con el número de referencia FFI2014-52989-C2-2-P, financiado por Ministerio de Economía y Competitividad. 
«Me empezó a gustar la literatura por culpa de la colección Araluce, suculentamente subtitulada Las obras maestras al alcance de los niños». Con estas palabras, el poeta, ensayista y traductor Luis Alberto de Cuenca (Madrid, 1950) arrancaba su artículo «Mi biblioteca de la colección Araluce», publicado en El Ciervo (2008), donde recordaba que su inclinación por la literatura y su dedicación a ella y a la creación artística tenían un origen concreto: el descubrimiento de las adaptaciones literarias de los clásicos preparados por la editorial barcelonesa.

El de Cuenca es un testimonio, pero hay muchos más que podrían avalarlo: Carmen Martín Gaite (García Padrino 2011, 33), Martín de Riquer ${ }^{1}$, Carmen Bravo-Villasante $(1989,21) \ldots$, y el de tantos y tantos chiquillos y jóvenes que leyeron y releyeron los volúmenes hasta que las cubiertas quedaban ajadas y sus páginas deshilachadas. Araluce se convirtió en el referente de muchas generaciones españolas y extranjeras que pudieron acercarse a la Literatura (en mayúsculas) gracias a las adaptaciones de las grandes obras.

Las razones del éxito de la colección fueron diversas: pequeño formato, precio económico, calidad de los materiales, una buena red de distribución por España, Europa y Sudamérica... Pero sobre todo hay dos factores que marcaron las claves del triunfo: la selección de los adaptadores y la de los ilustradores. Ramón de San Nicolás Araluce, propietario de la editorial, no dudó a la hora de crear un equipo de trabajo formado por especialistas en literatura infantil, como lo fue María Luz Morales, y por los más exquisitos artistas plásticos del momento.

\section{La editorial Araluce}

\subsection{Ramón de San Nicolás Araluce y su editorial}

La editorial Araluce nació como un proyecto empresarial ideado por Ramón Donato de San Nicolás Araluce (Santander, 1865-Barcelona, 1941) -en adelante, Ramón de S. N. Araluce (nombre con que editaba)-. Hijo de Agustín de San Nicolás Zabalbeitia y de Crisanta Araluce y Bellido, marqueses santanderinos, partió de joven a México D. F. en busca de fortuna huyendo de las desavenencias familiares ${ }^{2}$. Después de desempeñar numerosos oficios, entró a

${ }^{1}$ Declaraciones del propio Martín de Riquer en el programa Mujeres para un siglo, dedicado a María Luz Morales. http://www.rtve.es/alacarta/videos/mujeres-para-un-siglo/ mujeres-para-siglo-maria-luz-morales-escritura/713438/.

2 Agradezco a Pedro L. Yúfera, bisnieto de Ramón de S.N. Araluce, la información que me ha proporcionado sobre la familia para la redacción de este apartado. Parte de esta bio- 
trabajar en la editorial de Juan de la Fuente Parres, situada en el callejón de Santa Inés, número 5, de Ciudad de México. Con el tiempo fue ascendiendo en la empresa, llegando a ser director de ella y acabó comprándola ${ }^{3}$.

Tras vivir varios años en México, se instaló en 1898 en Barcelona, donde tenía sede editorial, y fue liquidando paulatinamente la empresa mexicana. A su llegada, aprovechó su experiencia sudamericana en el mundo de la impresión de libros y abrió la editorial que llevaba su nombre, una empresa que inicialmente estaba ubicada en la calle Bailén número 107 y que, poco después, se trasladó a la calle de las Cortes número 392, actualmente Gran Via de les Corts Catalanes, esquina con la calle Llançà.

Ramón de S. N. Araluce participó activamente en las asociaciones gremiales barcelonesas -entre ellas, el Centro de la Propiedad Intelectual y la Cámara del Libro (Llanas 2005, 247-248)-, fue vocal de la Junta fundacional de la Casa de América en Barcelona (Dalla-Corte 2013, 29), cónsul honorario de México en dicha ciudad y presidente de la Cámara de Comercio Mexicana en España, nombramientos estos que evitaron que durante la guerra civil se emprendieran acciones contra él, su empresa o su familia. Ventura Bover, titular de la empresa durante los años sesenta, recoge una semblanza del editor santanderino en un comunicado que envía al Jefe de Registro de Empresas el 23 de septiembre de $1967^{4}$ :

Fue uno de los fundadores de la Cámara Oficial del Libro de Barcelona, convertida luego en la actual Delegación del Instituto Nacional del Libro. Fue durante años miembro activo de la Junta y patrocinó, con don Vicente Clavel, de Editorial

grafía y de la de Morales procede del trabajo Julio (2019), si bien se aportan algunos datos nuevos y se concretan fechas y lugares, fruto de investigaciones posteriores.

${ }^{3}$ Según la Guía de Editores (1976) y la declaración de Enrique Ventura Bover ante el Ministerio de Información y Turismo, Araluce fundó la empresa en 1872, año totalmente improbable porque por entonces apenas tenía siete años y todavía vivía en España, bajo la tutela de los marqueses. Puede que esa fecha corresponda a la fundación de la empresa de De la Fuente Parres, que adquirió posteriormente Araluce. Los libros que he podido localizar en México publicados por la «Editorial de Ramón de S. N. Araluce» (nombre de la empresa en tierras sudamericanas) datan de 1899. A partir de 1900 el santanderino ya publica en Barcelona con el nombre de «Editorial Araluce».

${ }^{4}$ Con la implementación de la Ley de Prensa e Imprenta, popularmente conocida como la Ley Fraga, el 18 de marzo de 1966, se substituía la censura obligatoria por la mal llamada «censura voluntaria» y se obligaba a las empresas a obtener un número de registro. La concesión de este no se realizaba automáticamente y su denegación se convirtió en un excelente elemento de represión y control. Las empresas que no contaban con dicho número debían pasar obligatoriamente por la consulta voluntaria (lo que no deja de ser contradictorio); las que ya lo tenían no estaban obligadas a pasar por la censura voluntaria, aunque lo hacían de manera preventiva, ya que la Administración siempre podía incautarse de los ejemplares publicados y secuestrar la edición si así lo consideraba oportuno, con las consiguientes pérdidas económicas que todo ello suponía. 
Cervantes, la fiesta denominada «Día del libro», hoy de ámbito nacional. Su gran labor cultural, de elevado espíritu nacional, en el campo de la edición, es sobradamente conocida y fehaciente testimonio de su patriotismo. Los sufrimientos de todo género que tuvo que soportar durante la Guerra de Liberación Nacional en esta zona, quebrantaron su salud, falleciendo el $1^{\circ}$ de enero de $1940^{5}$.

Acabada la guerra, Araluce continuó con la edición de libros, en la medida en que las dificultosas circunstancias se lo permitieron, pues «el agotamiento de los fondos, la falta de papel y las trabas puestas a la exportación» (Abellán $1980,17)$ fueron escollos casi insalvables para muchos editores tras la contienda civil ${ }^{6}$. Ramón de S. N. Araluce murió en la ciudad de Barcelona el 1 enero de 1941, a la edad de 76 años.

Araluce, hombre experimentado en el mundo editorial, supo abrirse camino en la procelosa Barcelona de principios de siglo y encontró su espacio en el mundo de la edición infantil y juvenil ${ }^{7}$. La relativa poca presencia de editores especializados en este campo propició un proyecto, original por aquel entonces, que tuvo una amplia acogida ${ }^{8}$. Echando un vistazo al mercado editorial extranjero, Araluce pronto advirtió el éxito de algunas editoriales inglesas que habían encontrado un filón en la adaptación de obras clásicas para el público infantil y juvenil. Se interesó por esas propuestas editoriales y las adaptó al escenario español (García Padrino, 1999).

Si bien es cierto que la idea de Araluce arranca de los clásicos ingleses, no hay que descuidar un proyecto similar que desarrollaba el burgalés Saturnino Calleja (1853-1915) en el Madrid del último cuarto del XIX y que sería continuado por su hijo Rafael en el siglo XX. Por lo tanto, Calleja y Araluce se van a convertir en los principales promotores del libro infantil y juvenil en España desde las dos principales capitales editoriales del país, Madrid y Barcelona.

A la muerte de Araluce, su hija adoptiva, Rosa de San Nicolás Araluce (Barcelona, 1898-1978) ${ }^{9}$, heredó el negocio familiar, un negocio que fue decayendo

${ }^{5}$ El año no es exacto. En la partida de defunción de Ramón de S. N. Araluce que se conserva en el Registro Civil de Barcelona figura el año de 1941.

${ }^{6}$ Abellán, en su trabajo sobre la censura, señala: «Recién ocupada la ciudad de Barcelona por las tropas franquistas, la Cámara Ofícial del Libro de dicha ciudad elevó al jefe de Prensa y Propaganda de Burgos [Dionisio Ridruejo] un memorándum sobre 'Actualidad de la industria editorial española' en el cual se subrayaban las dificultades de los miembros del gremio» $(1980,17)$. A las ya indicadas más arriba añade la del exilio de muchos editores.

7 Además de literatura infantil y juvenil, el catálogo de la editorial ofrecía una variada y surtida oferta de colecciones, que iba de los manuales escolares a la literatura de ficción, pasando por monografías especializadas en el ámbito de las ciencias sociales y de las ciencias experimentales. Sobre la actividad de la editorial Araluce, véase Llanas (2005, 248-250).

${ }^{8}$ Sobre un panorama de las editoriales dedicadas a la literatura infantil a principios de siglo, consúltese García Padrino (2016).

${ }^{9}$ El verdadero nombre de Rosa de San Nicolás Araluce era Rosa Crisanta Padró y Busquets. La madre se casó con un médico que se internó en la selva mexicana y desapa- 
por el descuido de la propietaria, al parecer más interesada en que las ediciones se preparasen al modo tradicional que había instaurado el patriarca que en las innovaciones que se imponían en el mundo editorial de la Barcelona de medio siglo. La reticencia de Rosa de San Nicolás a modernizar la empresa y a adaptarla a los nuevos aires, llevó al cierre del negocio de la actual Gran Via.

Según Pascual (2010), a finales de los años 50, la editorial deja prácticamente de funcionar y el venerable edificio que albergaba la editorial fue comprado por Núñez y Navarro y convertido en un bloque de viviendas. Pero esta información no concuerda con los datos de los expedientes de censura, ya que, durante los primeros años sesenta, en las instancias que presenta Pedro Yúfera Jorquera (1888-1964), esposo de Rosa de San Nicolás y representante de la editorial ante la Delegación Provincial, continúa figurando la dirección de siempre: Avenida de José Antonio, no 392, nombre con que fue bautizada la calle de las Cortes tras el triunfo de los sublevados. Su bisnieto afirma que fue a principios de los sesenta cuando la editorial deja de funcionar. No obstante, por la documentación de que disponemos, la empresa no desaparece, y en $1967 \mathrm{su}$ propietario, Enrique Ventura Bover, que había entrado a trabajar en la editorial con 15 años, en 1923, solicita y obtiene el número de registro de empresas editoriales para la Editorial Araluce ante el Ministerio de Información y Turismo. Entre las colecciones que tiene la editorial, por esa fecha, se señalan: "Grandes figuras de la historia», "Las obras maestras al alcance de los niños», «Los mejores cuentos de todos los países», «Obras de Balmes» y «Obras de la Dra. María Montessori». La editorial Araluce continuó editando, aunque a un ritmo lento, y cerró definitivamente sus puertas en 1975.

\subsection{Datos biográficos de María Luz Morales}

María Luz Morales Godoy nació en La Coruña el 23 de abril de $1890^{10}$ y se trasladó con su familia a Barcelona en 1897. Estudió Filosofía y Letras en la Universidad de Barcelona y Pedagogía en el antiguo Seminario de Pedagogía de la Mancomunidad de Cataluña. Empezó a publicar como escritora y adaptadora en 1914 para la editorial Araluce. Su carrera profesional como periodista arrancó en 1921 al obtener el cargo de directora de El Hogar y la Moda, revista barcelonesa dedicada al público femenino, de periodicidad mensual y ámbito nacional. En ese mismo año, la Sociedad General de Publicaciones

reció. Al no encontrarse su cuerpo, no se la pudo dar por viuda ni tampoco pudo volver a casarse, puesto que ya lo estaba. Cuando se unió a Ramón de S. N. Araluce, este adoptó a la hija, que, a su vez, tomó sus apellidos.

${ }^{10}$ Sobre el lugar y día de su nacimiento coinciden todos sus biógrafos, no así en el año: García Padrino $(1999,146)$ y Servén Díez $(2016,177)$, apuntan como año 1898, mientras que Albertí $(2015,33)$ señala el año de 1889 . Yo tomo el dato de 1890 de su partida de defunción, que se conserva en el Registro Civil de Barcelona. 
editó su primera traducción, Los ojos de Alicia, de Charles E. Pearce -preparada en colaboración con su prima Zoé Godoy- y comenzó a publicar sus artículos de manera esporádica en La Vanguardia; tres años después, el rotativo barcelonés le encargó el análisis semanal de la cartelera cinematográfica y, en 1933, pasó a ocuparse de la sección de crítica teatral. En 1926 se le ofreció colaborar en el diario madrileño El Sol, fundado por Nicolás María de Urgoiti, con una página semanal fija, "La mujer, el niño y el hogar», además de los artículos literarios que publicaba en este mismo periódico. Desde las páginas de El Sol desarrolló sus ideas en torno al proceso y hábito de la lectura en los niños, ejerció una importante labor como promotora y divulgadora de la lectura infantil, y desarrolló un proyecto que todavía hoy sorprende por su agudeza y modernidad. Sus reflexiones quedan recogidas en Libros, mujeres, niños, un pequeño volumen premiado en la III Feria del Libro de Barcelona y publicado en 1928 por la Cámara Oficial del Libro ${ }^{11}$. Su colaboración con el rotativo madrileño se mantuvo hasta su cierre, en 1936.

Antes de la Guerra Civil, formó parte del Patronato de la Residencia de Señoritas Estudiantes de Barcelona, centro dirigido por María Solá de Sellarés (Fulcarà Torroella 2011, 21-23) ${ }^{12}$, y participó activamente en las asociaciones femeninas, como el Club Femení d'Esports de Barcelona o el Lyceum Club de Barcelona, entidad de la que fue cofundadora con Aurora Bertrana.

Con el estallido de la guerra de 1936, el Gobierno de la Generalitat decretó el embargo de algunos periódicos, entre ellos, La Vanguardia, que quedó en manos de un comité obrero, que la nombró directora el 7 de agosto de 1936. De este modo, a sus 46 años se convirtió en la primera directora de uno de los periódicos de más tirada en España. Acabado el conflicto bélico y con Franco al frente del gobierno, fue detenida y, después de un tiempo en la cárcel, retomó su actividad como periodista ocasional firmando sus artículos con seudónimo o anónimamente, y ejerció de traductora para diversas editoriales de la época (Servén Díez 2016; Julio 2017). En 1948 recuperó el carnet de periodista y entró a formar parte del Diario de Barcelona, donde publicó artículos literarios y crónicas de teatro y de moda durante más de veinticinco años. En 1960 fue readmitida como socia en la Asociación de Prensa de Barcelona, entidad de la que había formado parte durante los años veinte. También colaboró, aunque de manera más esporádica, en El Noticiero Universal y La Hoja del Lunes (Albertí 2015, 45). Su labor como periodista se alternó con las tra-

${ }^{11}$ Servén Díez (2012) reivindica la actividad de Morales como promotora de la lectura infantil, aspecto este descuidado de momento por muchos estudiosos.

12 En diversos trabajos (Rodrigo 2002; Albertí 2015; Servén Díaz 2016) se afirma que María Luz Morales dirigió la Residencia Internacional de Señoritas Estudiantes, pero lo cierto es que únicamente formó parte de su Patronato. Su labor, junto con la de Candelaria Escolar, al frente del centro fue de gran valor, pero no ejerció tal cargo (Fulcarà Torroella 2011, 111). 
ducciones de ensayo, narrativa y piezas dramáticas (muchas de ellas inéditas), y con la escritura de creación propia y la dirección de colecciones editoriales.

María Luz Morales murió el 22 de septiembre de 1980, a la edad de 90 años, rodeada de premios y distinciones ${ }^{13}$.

\section{Colecciones infantiles y juveniles de Araluce}

Ramón de S. N. Araluce capitaneó un proyecto que pretendía acercar los clásicos de la literatura universal a los niños. Así que, a través de sus conocidos, contactó con una joven escritora de cuentos, María Luz Morales, para que preparara las adaptaciones de la colección, y con un pintor valenciano, José Segrelles Albert (Albaida, 1885-1969), que empezaba a despuntar por aquel entonces, y que debía encargarse de las ilustraciones. Del tándem Morales-Segrelles salieron 19 volúmenes, de los 30 que preparó la periodista para la editorial.

Araluce arrancó su aventura en el mundo de las publicaciones para los más jóvenes con la colección «Las grandes obras maestras al alcance de los niños», antes de $1912^{14}$, y su éxito contribuyó a la creación de dos colecciones más: «Grandes hechos de los grandes hombres» $\mathrm{y}$ «Páginas brillantes de la historia», ya a mediados de los años veinte, momento en que el género se fue consolidando y en que las editoriales infantiles y juveniles recibieron subvenciones públicas a fin de promocionar el fomento de la lectura.

\subsection{Las obras maestras al alcance de los niños}

Los volúmenes de «Las obras maestras al alcance de los niños» eran impresos en $8^{\circ}$, medían $15 \times 12 \mathrm{~cm}$, estaban encuadernados en tela con estampaciones doradas y contaban entre unas 120-160 páginas de texto a las que se añadían nueve ilustraciones a plana entera. Con esas dimensiones, la lectura se hacía agradable y atractiva, y los libritos se ajustaban al tamaño de las manos de los niños. La colección llegó a contar con 93 volúmenes, y de algunos de ellos se llegaron a hacer numerosas ediciones a lo largo de casi 60 años ${ }^{15}$. El propósito de la colección, como reza en las promocionales páginas finales de

${ }_{13}$ Una biografía más detallada de María Luz Morales puede consultarse en Rodrigo (2002), Albertí (2015) y Julio (2017).

${ }^{14}$ No sabemos exactamente cuándo apareció el primer volumen puesto que los primeros tomos no llevan año de edición y solo lucen el Nihil Obstat de la censura eclesiástica de 1914. No obstante, por la enseña que luce como muestra de calidad en las primeras páginas de los volúmenes, la colección había sido «declarada de utilidad pública por el Estado español en 29 de junio de 1912», por lo que por esa fecha ya estaba en el mercado.

15 Por ofrecer algunas muestras, Los héroes conocieron una 7. a edición, La Divina Comedia llegó a la 8. y Los Cuentos de Grimm hasta la 10. ${ }^{a}$ Hay que puntualizar que no 
algunos títulos, no era otro que «poner al alcance de la inteligencia infantil las obras maestras que de la literatura han producido los más gloriosos genios de todos los países y de todas las épocas, todo ello descrito de una manera agradabilísima y amena» (Morales 1940, 124).

No podemos asegurar si Morales sugirió los títulos que adaptó para Araluce, pero todo lleva a pensar que, si no los decidió ella directamente, su criterio sería atinadamente atendido por el propietario de la editorial, pues basta echar una ojeada a la lista de libros para el público infantil que ofrecía en su Libros, mujeres, niños (1928) y compararla con los catálogos que publicó el editor santanderino para observar que la mayoría de ellos tuvieron cabida en la colección ${ }^{16}$.

Los primeros ocho volúmenes de "Las obras maestras al alcance de los niños» fueron traducciones directas de las versiones de textos clásicos de la literatura universal, preparadas por H. E. Marshall, C. E. Smith, Jeanie Lang, Amy Heedman o Mary MacGregor, entre otros ${ }^{17}$. Los primeros títulos son los siguientes:

1. Historias de Shakespeare, adaptadas por Jeanie Lang, con ilustraciones de N. M. Prince.

2. Los héroes, de Charles Kingsley, adaptada por Mary MacGregor, con ilustraciones de F. de Myrbach.

3. La Divina Comedia, de Dante, adaptada por Mary MacGregor, con ilustraciones de R. T. Rose.

4. Historias de Andersen, adaptada por Mary MacGregor, con ilustraciones de Olive Allen.

5. Guillermo Tell, adaptada por H. E. Marshall, con ilustraciones de I. L. Gloag.

6. Cuentos de Grimm, adaptados por Amy Heedman, con ilustraciones de Harry Rowntree.

todas las tiradas tenían el mismo número de ejemplares. Las de esta colección oscilaban entre los 2000 y los 6000 .

16 La lista de libros que confecciona para el apartado de «Ensayo de biblioteca infantil», que recoge en las últimas páginas del libro, está formada por 148 títulos, además de la indicación genérica de «Biografías amenas y sencillas de los grandes hombres» y «Vulgarizaciones sencillas», divididos en cuatro secciones en función de la edad, siguiendo la propuesta de Marcelo Braunsvich: «De cinco a siete años: álbums, libros de estampas», «De siete a diez años: cuentos y leyendas», «De diez a trece años: historias infantiles, adaptaciones de obras maestras» y «De trece a quince años: relatos, novelas de aventuras y viajes».

${ }_{17}$ Como señala García Padrino (1999, 142), el interés por acercar las grandes obras universales al público infantil y juvenil tiene un precedente claro que se remonta a la Inglaterra de principios del siglo XIX. Thomas Hodgkin, seudónimo del escritor y filósofo anarquista William Godwin, edita para su colección «Biblioteca Juvenil» Tales from Shakespeare. Designed for the Use of Young Person (1806), una adaptación en forma de relato de algunas piezas dramáticas de Shakespeare, que sale de la pluma de los hermanos Mary y Charles Lamb. Esa iniciativa tuvo una continuidad que se materializó en la labor que realizaron diversas editoriales inglesas a principios del siglo XX. 
7. Viajes de Gulliver a Liliput y Brodignac, de Jonathan Swift, adaptada por John Lang, con ilustraciones de F. M. B. Blaikie.

8. Historias de Wagner, adaptadas por C. E. Smith, con ilustraciones de Byam Shaw.

Poco a poco, Araluce introdujo en su colección versiones de clásicos españoles y universales - de hecho, los volúmenes 9 y 10 corresponden a $E l$ Quijote- y en ediciones posteriores, llegó incluso a crear versiones propias de algunos de estos ocho primeros volúmenes traducidos, con adaptaciones que encargaba a Manuel Vallvé, Francisco Esteve y, especialmente, a María Luz Morales. Así, por ejemplo, las Historias de Shakespeare fueron adaptadas por ella e ilustradas por Segrelles, como también lo fueron los Cuentos de Grimm (con dibujos de Albert ${ }^{18}$ ) y los Viajes de Gulliver a Liliput y Brodignac (con ilustraciones de A. de la Portilla). En el caso de La Divina Comedia y Guillermo Tell, Araluce mantuvo la adaptación de MacGregor y de Smith, pero con ilustraciones firmadas por Segrelles y Albert, respectivamente.

Morales fue una de las adaptadoras más fecundas de Araluce. De los 93 volúmenes de que constaba la colección, 27 de ellos fueron preparados por ella ${ }^{19}$; dicho de otro modo, el $29 \%$ de la colección, casi un tercio, recayó en ella. No extraña, pues, que Martín de Riquer al recordar los libros de Araluce afirmara que «todos nos amamantamos a las ubres de María Luz Morales, que era la inolvidable adaptadora de tantas historias» (Masoliver 1983, 42). Y, en efecto, su acierto en la selección de los títulos y su habilidad para dirigirse a los niños dejó huella en muchos de ellos, que se iniciaron en la lectura a través de sus textos. Y ese era el propósito de Morales, que siempre consideró que

Para la biblioteca del niño los mejores libros son... los libros mejores; los más bellos, los más pura y sinceramente sentidos y escritos. Muchos que no se crearon, ni remotamente, para ser leídos por niños, gustan tanto a los chiquillos que, con una inteligente revisión y supresiones levísimas, podrían ser considerados como clásicos de la infancia $(1928,80)$.

Su labor para la colección era, además de la posiblemente selección de títulos -como ya he apuntado-, el de su adaptación y no el de la traducción propiamente. Ya lo señalaba Servén Díez en uno de sus trabajos sobre Morales: «La labor de la joven para esta colección consiste más en una adaptación y presentación de textos que en una traducción sobre originales en lengua extranjera» $(2016,180)$. Efectivamente, su cometido era el de la adaptación, que en ocasiones bordeaba la recreación literaria:

18 García Padrino (2016, 38, n. 20) nos informa de que Segrelles firmaba sus ilustraciones con el nombre de «José Segrelles» o «Albert» (su segundo apellido). Por lo tanto, estaríamos hablando de un solo ilustrador.

19 Ofrecemos el listado completo en el anejo final. 
Más bien podrían considerarse [sus versiones] como creaciones, pues la nueva elaboración de las grandes obras de la literatura universal al alcance de los niños exige capacidad creadora y originalidad. Ambas cosas las posee María Luz Morales y además extraordinaria sensibilidad (Bravo Villasante 1985, 205).

Además de los textos originales (si eran españoles) o de las obras traducidas, podía utilizar otros materiales complementarios que la ayudaban a pergeñar su versión. En una nota filológica que aparece en el prólogo de Las hazañas del Cid confiesa que para preparar el texto ha tenido a la vista «Cantar de Myo Cid» (ed. de Clásicos Castellanos, Madrid, 1913); «Romancero selecto del Cid», de Manuel Milá y Fontanals (1884); «La Castilla y el más famoso castellano», del Padre Manuel Risco, y la «Leyenda del Cid», de José Zorrilla.

Analizados los volúmenes que adaptó para la colección, se puede ver que su modus operandi para preparar las versiones era distinto según el género del libro de partida:

a) En las novelas extensas, seleccionaba los pasajes más característicos y los reescribía con sus propias palabras. Así, La Ilíada o La Odisea son el resultado de un compendio antológico de episodios explicados con un lenguaje sencillo y ameno para los niños.

b) Para los volúmenes de cuentos de un autor, escogía los que podían ser más atractivos o conocidos, los simplificaba desde el punto de vista argumental y los reescribía adaptándolos a su nuevo público. Así procede en Los cuentos de Grimm o Los cuentos de Perrault.

c) En cuanto a los volúmenes dedicados a los dramaturgos, seleccionaba las obras teatrales más relevantes y las convertía en texto narrativo, espigando las escenas más significativas. Obsérvese que esos volúmenes, manipulados desde el punto de vista del fondo y de la forma, llevan el título de «Historias de...» y el nombre del dramaturgo (por ejemplo, Historias de Esquilo o Historias de Ruiz de Alarcón), porque lo que se recoge en esos tomitos son los argumentos narrados de esas obras teatrales, no los diálogos dramatizados. Así lo confiesa la propia adaptadora en el prólogo a Historias de Lope de Vega:

Tal como Lope de Vega escribió estas obras son un drama y dos comedias vestidos con el suntuoso ropaje de los sonoros versos castellanos. En prosa lisa y llana, tal como hoy os las ofrecemos, pierden mucho de su belleza original. Son, en cambio, mucho más comprensibles para vuestras imaginaciones infantiles, que pueden seguir así el hilo de la fábula y recrearse con la grandeza de las situaciones $(1940,12)$.

d) En el caso de los textos españoles, además de seleccionar los pasajes y prosificar los argumentos (en caso de que estuvieran en verso), moderniza el lenguaje para facilitar la intelección del niño y evitar el aire 
arcaico de algunos de los títulos seleccionados. Esa labor se aprecia en el prólogo a Las hazañas del Cid, donde señala: «El castellano del Myo Cid [...] apenas podemos hoy entenderlo sin tener a mano una traducción moderna» $(1944,10)$, o en el de las Historias del romancero, donde apunta:

Los romances, como sabéis, están compuestos en un lenguaje llano y fácil, pero en forma de verso-romance-asonantado, y sembrados de vocablos antiguos (arcaicos), que hoy, sin una preparación, tal vez no entenderíais. Yo quiero relatároslos en sencilla prosa, procurando deformar lo menos posible así el fondo como la forma, y dejando intercalados aquellos versos - generalmente los diálogos- que me parecen fundamentales, o que son de una belleza intraducible $(1939, \mathrm{X})$.

Y esa fue su labor en la colección: adaptar o reescribir los grandes textos literarios para acercarlos a los más jóvenes a fin de sembrar en ellos la semilla de una curiosidad que los llevara más adelante a la lectura de los originales, todo ello con una sensibilidad y delicadeza admirables.

\subsection{Grandes hechos de los grandes hombres}

La segunda colección que Araluce sacó al mercado, en torno a la segunda mitad de los años veinte, fue «Grandes hechos de los grandes hombres». El público al que iba dirigido era el juvenil. Los volúmenes presentaban un aspecto muy similar a los de la colección anterior: encuadernación en tela con estampaciones doradas y contaban entre unas 136-180 páginas de lectura más nueve ilustraciones en colores, pero diferían un poco en el tamaño, ya que este era algo mayor: medían 17,5 x $12 \mathrm{~cm}$.

La colección llegó a contar con 43 títulos dedicados a los personajes más variados de la historia: descubridores (Cristóbal Colón, Alvar Núñez Cabeza de Vaca, El gran Capitán, Juan Sebastián Elcano), escritores (Fray Luis de León, Calderón de la Barca, Francisco de Quevedo), reyes españoles (Felipe II o Carlos V), estrategas extranjeros (Julio César, Napoleón), hombres de ciencia (Arquímedes, Miguel Servet), artistas (Francisco de Goya, Leonardo da Vinci), etc. El objetivo de la colección, como la editorial declaraba a la hora de promocionarse, era presentar «hechos y acontecimientos de los grandes hombres que la fama inmortalizó y a quienes las generaciones rinden culto. Narraciones amenas y sugestivas, llenas de emoción».

Para esta colección, Morales solo preparó tres volúmenes. El primero de ellos apareció en 1926 y, en él, retrata una de las figuras más caras de la literatura española: la del autor de El Quijote. El tomito, ilustrado por José Segrelles, consta de 160 páginas y lleva por título Miguel de Cervantes. Su vida gloriosa relatada a la juventud. A través de los doce capítulos en que divide 
el libro, repasa los años de mocedad del autor alcalaíno, su enrolamiento como soldado y su participación en Lepanto, el cautiverio, el encuentro con el rey Azán, el rescate de los trinitarios, las andanzas por la península, sus primeras obras, sus dificultades, la creación de El Quijote, la aparición de las Novelas Ejemplares y del falso Quijote, para acabar contándonos los últimos días del ilustre escritor.

El propósito de la colección y de Morales era una vez más la promoción de la lectura, en este caso acercando las grandes figuras de la historia a los jóvenes. Las palabras del prólogo de esta obra resumen con nitidez el espíritu de la colección:

Tal es el objeto de este libro, en que grandes hechos se relatan con sencillas palabras, y en que, paso a paso, brevemente pero respetuosamente, se sigue vida tan fecunda. El libro es pequeño, pero grande la vida, la figura que en él se refleja. Y pues que del libro no hay más que decir, apresuraos a volver la hoja y veréis lo que más os interesa: la figura, el hombre (1926, VIII).

El segundo libro que preparó, Vida y hechos de Alejandro Magno, era un tomito de 159 páginas, ilustrado también por Segrelles. El volumen, encabezado por un prólogo de la autora, está dividido en once capítulos en los que Morales relata la infancia y juventud de Alejandro, las guerras en las que participó y el fin de Filipo, su etapa como rey de Macedonia, la conquista de Persia, su enfrentamiento con Darío, la batalla de Isso, el sitio de Tiro, la fundación de Alejandría, la batalla de Arbelas, las conquistas de la India, y el final de Alejandro: «Así fue Alejandro, grande en la paz y en la guerra. Nada importa que, afortunadamente, no sea nuestra época propicia al fragor guerrero. La compañía de los grandes nos engrandece: adentrémonos, pues, en la de Alejandro Magno» (1926, VIII). Con estas animosas palabras, Morales convidaba a los jóvenes a sumergirse en la vida de uno de los más grandes estrategas de la historia.

El tercer y último volumen, con ilustraciones de Albert y dedicado a Julio César, también constaba curiosamente de 159 páginas (igual que el anterior) y llevaba por título Julio César: Vida y hechos. Tras un prólogo elogioso en el que define al prócer romano como un personaje ambicioso, pero generoso «para con sus compañeros de armas», destaca «su amor por el pueblo, su clemencia para con el delincuente, su piedad para con el vencido... De todo esto van a hablaros largamente, repetidamente, su vida y sus hechos» (1926, VIII), y relata su vida en doce capítulos: la época de César, su juventud, la etapa de pontífice, pretor y cónsul, la aventura en las Galias, los nuevos triunfos, las invasiones de las Islas Británicas, las luchas contra Vercingetórix, el enfrentamiento civil con Pompeyo, su expansión por Oriente, su estadía en Alejandría, su etapa de dictador y su funesto final.

Para la preparación de estos volúmenes, Morales selecciona los hechos más significativos y variados de la vida de estos personajes, para que el lector ex- 
traiga de ellos una visión lo más completa posible, y relata sus vidas siguiendo la misma técnica del relato, próxima al cuento, que utiliza siempre que se dirige a un público infantil y juvenil.

\subsection{Páginas brillantes de la historia}

La tercera colección que Araluce sacó para los niños y jóvenes fue «Páginas brillantes de la historia» y data de 1927. Morales no intervino directamente en ella, en tanto que no preparó ninguno de los volúmenes, pero tal vez sugiriera alguno de los títulos. De la colección salieron 39 volúmenes, algunos de ellos dedicados a hechos históricos o a protagonistas de la Historia: Las Cruzadas, Francisco de Pizarro, Hernán Cortés, Isabel la Católica, Raimundo Lulio, Los héroes de Trafalgar, Santa Teresa de Ávila, Los Incas, Sagunto, Numancia, Aristóteles, Demóstenes... y en ellos se presentaban, como indica la publicidad, «narraciones de los hechos más salientes y trascendentales de la Historia, expuestos en forma interesantísima, llena de encantos y bellezas».

El aspecto físico de los volúmenes era idéntico al de los «Grandes hechos de los grandes hombres»: encuadernación en tela de $17,5 \times 12 \mathrm{~cm}$, con cubierta dorada y nueve láminas ilustradas. De hecho, algunos de los libros dedicados a estos personajes podían haber formado parte de la colección anterior.

Y es que, en realidad, la selección de los títulos de estas dos últimas colecciones no es en absoluto gratuita. Como veremos más adelante, estas colecciones nacen al amparo del éxito de la primera colección y de las subvenciones públicas decretadas por Primo de Rivera como promoción de la lectura. Esas ayudas gubernamentales podrían justificar, desde un punto de vista ideológico, el contenido de los volúmenes, que se convierten en obras de difusión propagandística en las que se destacan hazañas, acontecimientos y personajes españoles grandiosos y se exaltan unos valores nacionales y de culto a los héroes que configurarán el imaginario de una España digna con un pasado glorioso. De este modo se va fraguando la idea de una grandeza imperial que bien se compaginará más adelante con la retórica oficial del franquismo. Porque es indiscutible, como apunta Bravo-Villasante, que «los libros para niños también responden a un propósito pedagógico y formativo», pero asimismo son una «muestra evidente de que la literatura infantil es un instrumento propagandístico de una política» $(1989,28-30)$.

\section{Difusión de las COleCCIONES: Utilidad PÚBliCA Y PRIVADA}

La historia de las colecciones de Araluce para el público infantil y juvenil corre pareja con la historia de las bibliotecas escolares en España. Los tímidos intentos de finales del XIX por crear bibliotecas en las escuelas, se materiali- 
zaron en la primera década del siglo $\mathrm{XX}^{20}$. El Real Decreto de 30 de abril de 1909 establecía los diferentes tipos de bibliotecas que debían crearse para fomentar la cultura popular y determinaba que la selección de sus fondos recaía en la Junta Facultativa de Archivos, Bibliotecas y Museos. Según esta disposición, los libros escogidos eran aquellos que habían obtenido un informe favorable del Consejo de Instrucción Pública o de una de las Academias Reales, y dicho informe debían solicitarlo expresamente los autores o editores, que lo utilizaban para exhibirlo como muestra de calidad o para beneficiarse de las subvenciones del Estado.

A fin de agilizar la llegada de los libros a los diferentes rincones de España, se crearon las bibliotecas escolares circulantes, pues, en palabras del ministro de Instrucción Pública y Bellas Artes, don Santiago Alba:

\begin{abstract}
Una de las más urgentes necesidades en nuestras escuelas, tanto para los maestros como para los niños, es la de libros adecuados que difundan en la forma amena y atractiva de la lectura, los elementos de cultura general y, lo que es más importante, el estímulo para que se despierte el interés hacia ella (Gaceta de Madrid, $n^{\text {o }} 329,24 / 11 / 1912$, p. 511).
\end{abstract}

Se crea así por Real Orden, firmada por el rey Alfonso XII, el 22/11/1912, «una Biblioteca popular circulante con destino a las Escuelas públicas, que dependerá de la Dirección General de Primera Enseñanza». El Ministerio de Instrucción Pública pidió al Museo Pedagógico Nacional un informe acerca de los fondos más adecuados para estas bibliotecas. Entre los títulos figuraban los de «Las obras maestras al alcance de los niños» de Araluce, y así lo exhibe el editor en la primera página de los volúmenes de la colección, como muestra de reconocimiento y prestigio:

Premiada en las exposiciones de Leipzig, Barcelona y Sevilla. Declarada de utilidad pública por el Estado español en 29 de junio de 1912 y de uso para las Bibliotecas Circulantes y Docentes. Adoptadas en las Escuelas nacionales por varios gobiernos americanos. Elegidas por distintos Ayuntamientos de España para premios en sus escuelas.

Araluce supo aprovechar la coyuntura de la creación de las bibliotecas escolares y circulares, así como las subvenciones públicas para ampliar su negocio:

En 1926 Primo de Rivera instituyó por decreto la Fiesta Nacional del Libro el 7 de octubre [...] El objetivo era promocionar el libro español, y para ello el decreto obligaba a todas las entidades que se beneficiaban de las subvenciones estatales a dedicar el 3 por cien de dicha subvención a la compra y el reparto de libros

20 Para conocer la creación y desaparición de las bibliotecas infantiles en España es imprescindible consultar Diego Pérez y González Fernández (2008). 
en esa jornada. Por otra parte, se obligaba a los ayuntamientos a gastar el uno por mil de su presupuesto a la misma tarea o a crear bibliotecas populares. Coincidiendo con la orden gubernamental algunas editoriales lanzaron ediciones especiales de literatura infantil y juvenil pensando probablemente en las ventajas que traería para el negocio editorial el fomento de la lectura en los niños. Entre esas editoriales se encontraba la ya mencionada Editorial Araluce (Sánchez García 2001, 349).

Es gracias a esas ayudas, y a la sombra del éxito de «Las grandes obras maestras al alcance de los niños», como nacen las colecciones «Los grandes hechos de los grandes hombres» y «Páginas brillantes de la Historia», cuyos títulos aparecen de manera continuada en los diferentes listados de obras imprescindibles para las bibliotecas escolares que durante algunos años preparó el Museo Pedagógico.

El doble objetivo de las bibliotecas escolares era, por una parte, contribuir a despertar en el niño el interés por la lectura y, por otra, servir de complemento de la labor docente del maestro (Luzuriaga, 1934). La República se preocupó especialmente de que el libro, que hasta entonces había sido considerado un artículo de lujo, se convirtiera en un artículo de primera necesidad. La aprobación del Real Decreto de 7 de agosto de 1931, que determinaba que toda escuela de primaria debía tener una biblioteca, y la creación de las Misiones Pedagógicas, que circularon por numerosos puntos de España, contribuyeron a la promoción del libro infantil, asesorada por especialistas y pedagogos; entre ellos, Lorenzo Luzuriaga, que en su librito Bibliotecas escolares (1934), elabora un «Catálogo de obras apropiadas para las bibliotecas escolares», en el que figuran las tres colecciones de Araluce: «Las obras maestras al alcance de los niños», «Los grandes hechos de los grandes hombres» y «Páginas brillantes de la Historia», con todos los títulos aparecidos hasta el momento. Y entre los libros repartidos por las Misiones Pedagógicas se encuentran algunos volúmenes de las colecciones de Araluce, como se comprueba en los inventarios que se han podido reconstruir de las bibliotecas escolares antes de la incautación, expurgo y destrucción sufrida a raíz de la Guerra Civil ${ }^{21}$.

Las colecciones de Araluce sobrevivieron a la guerra y continuaron formando parte de las bibliotecas particulares y públicas. La editorial reconocía en 1953 que «mis principales clientes son los colegios religiosos, no solo de España, sino también de toda América, la Junta de Adquisición de libros para Bibliotecas, y el Frente de Juventudes» y «son recomendados por los señores Catedráticos y Maestros a sus alumnos» (Expediente n ${ }^{\circ}$ 2945-53, del Archivo General de la Administración, Alcalá de Henares). Efectivamente, los volúmenes de la colección no solo fueron textos destinados a la lectura lúdica, sino

${ }^{21}$ Véase, por ejemplo, como muestra los Apéndices $\mathrm{n}^{\circ} 5 \mathrm{y} \mathrm{n}^{\circ} 6$ del trabajo de Diego Pérez (2011), donde figuran algunos de los volúmenes preparados por María Luz Morales para Araluce. 
que fueron textos de lectura recomendada en colegios y escuelas españolas y sudamericanas, propiciando no solo la formación de los niños, sino también la alfabetización de los adultos ${ }^{22}$.

Las colecciones de Araluce tuvieron una gran aceptación y sus volúmenes se convirtieron en los libros de lectura de numerosas generaciones. La amenidad con que se presentaban los textos, las prestigiosas ilustraciones salidas de las manos de José Segrelles o José Camins, y la calidad de los ejemplares a precios asequibles garantizaron el éxito. Del siguiente modo anunciaba La Vanguardia la aparición de los volúmenes El paraíso perdido y La infantina de Francia, en 1919:

Sabido es cómo presenta sus tomitos, verdadero encanto de la imaginación infantil, la casa Araluce. Editados con esplendidez y verdadero gusto, con ilustraciones de primer orden (para que el niño aprenda a distinguir lo artístico de lo chillón y vulgar), pocos libros hemos visto de ese carácter, lo mismo españoles que extranjeros, que los igualen, cuanto (sic) menos que los superen.

Por otra parte, se advierte el acierto en la selección de las obras y el arte de los adaptadores, que saben escribir para las jóvenes inteligencias, de modo que los niños comprendan bien cuanto se les dice y vayan adquiriendo afición, insensiblemente, a las obras que son consideradas como joyas de la literatura universal (06/03/1919, p. 11).

\section{Las colecciones de Araluce y la historia de España: censura ECLESIÁSTICA Y CENSURA CIVIL}

Con el triunfo de las tropas sublevadas se instaura en España un nuevo régimen político, cuyo primordial objetivo es el control y la represión. Todos los organismos y centros que se crean, y decretos y órdenes que se promulgan, van destinados a borrar el pasado del país, a diluir, cuando no a exterminar, todos los referentes culturales de la España republicana.

La primera orden de censura aparece firmada en Burgos por Ramón Serrano Suñer, ministro del Interior, el 29 de abril de 1938 (BOE 30/04/1938), casi un año antes del final oficial de la guerra civil, y se mantiene vigente hasta marzo de 1966, momento en que aparece la Ley de Prensa e Imprenta, alentada por Manuel Fraga Iribarne. Con la ley de 1938 se instauraba la censura obligatoria para cualquier publicación, periódica o no, inédita o ya editada, razón por la cual los pequeños libros de Araluce, incluso los impresos antes de la Guerra Civil, se vieron sometidos a los lápices de los censores, que deter-

${ }^{22}$ El mercado sudamericano fue muy lucrativo para Araluce. En los proyectos gubernamentales de alfabetización del campesinado de numerosos países de América del Sur entre ellos, Colombia-, los títulos de estas colecciones figuraban en los listados de libros que circulaban por el país, al modo de nuestras bibliotecas itinerantes republicanas. 
minaron la autorización, modificación o supresión de pasajes, palabras o capítulos en función de una serie de criterios no siempre definidos.

De los 27 títulos que María Luz preparó para la colección «Las obras maestras al alcance de los niños» se conservan 23 expedientes de censura en el Archivo General de la Administración de Alcalá de Henares (en adelante, AGA). No tenemos documentación acerca de Historias de Shakespeare, Tradiciones hispanas, Las mil y una noche, y La leyenda de Sigfrido. Tal vez sí pasaron por la censura civil y los expedientes se perdieron o se destruyeron ${ }^{23}$, o tal vez la autorización de la censura eclesiástica fue suficiente para darles vía libre, pues las autoridades eclesiásticas tenían mayor poder que las civiles en materia de censura, y las publicaciones religiosas o las que contaban con el beneplácito de las autoridades religiosas no estaban obligadas a pasar por la censura civil ${ }^{24}$.

Araluce en sus colecciones para niños y jóvenes siempre, desde las iniciales ediciones de 1914, imprimió en su primera página el Nihil Obstat de la autoridad eclesiástica competente:
Barcelona, 21 de octubre de 1914. Por lo que a Nos toca, concedemos nuestro permiso para la publicación de las obras que bajo el título de «Colección de obras maestras al alcance de los niños» dará a luz la Casa Editorial Araluce, de esta ciudad, mediante que de nuestra orden ha sido examinada, y no contiene, según la censura, cosa alguna contraria al dogma católico o a la sana moral. Hágase constar esta licencia al principio o al final del libro, en la forma anotada al margen, y entréguense dos ejemplares rubricados por el Censor, en la Curia de nuestro Vicariato. / El Vicario Capitular: José Palmarola. Por mandado de su señoría, Dr. P. Vallés, PBRO. Pro-Scrio.

A pesar de ello, los volúmenes de Araluce también pasaron por la censura civil. Los primeros expedientes de los textos adaptados por Morales para la colección «Las obras maestras al alcance de los niños» llevan la fecha de entrada de 2 de enero de 1942 y pertenecen a Los viajes de Gulliver a Liliput y

${ }^{23}$ En el traslado de los expedientes de censura del MIT al AGA se perdió numerosa documentación, por descuido, desidia o por un interés premeditado en hacerla desaparecer. Abellán (1980) ya denunció hace años que el número de expedientes del AGA era inferior al que él había podido consultar en los subterráneos del MIT cuando preparaba Censura y creación literaria en España (1939-1976). Muñoz Cáliz nos informa de la quema de expedientes a la muerte de Franco: «Según varios testimonios orales, la noche en que se conoció la muerte del dictador, se formó una hoguera en el patio del Ministerio de Información y Turismo, en la que fueron quemados los expedientes de censura que se encontraban allí en aquel momento. En otros casos, hemos encontrado expedientes incompletos debido a que parte del material quedó en poder de algún alto cargo al que se le consultó sobre la obra en cuestión, o expedientes que se encuentran ilocalizables por diversos motivos» (2006 LXXI, n. 191).

${ }^{24}$ Para un estudio más detallado de la acción de la censura en los volúmenes preparados por Morales para la editorial Araluce, véase Julio (2019). 
Brodignac, La Odisea, La gitanilla, Los cuentos de Grimm e Historias de Tirso de Molina. El censor consideró que las adaptaciones estaban pulcramente preparadas y podían ser publicadas, si bien señalaba para todos los casos: «Autorizada sin que aparezca el nombre de la adaptadora Luz Morales». Ante tal objeción la editorial retiró el nombre de Morales de las primeras páginas de las reediciones de ese año, y se puede comprobar que en los ejemplares de $L a$ Odisea anteriores a 1942 aparece el nombre de la adaptadora, mientras que en la reimpresión de 1942 su nombre ha desaparecido. La portada de la cuarta edición, de 1933, dice: «Homero / La Odisea / Relatada a los niños / por / María Luz Morales / con ilustraciones de José Segrelles»; en cambio, en la sexta edición, de 1942, se lee: «Homero / La Odisea / Relatada a los niños / con ilustraciones de José Segrelles».

Las objeciones del censor obedecían a motivos políticos. El 13 de febrero de 1939 el BOE había publicado la Ley de Responsabilidades Políticas, según la cual todos aquellos que habían colaborado con la República y habían tenido cargos debían asumir su responsabilidad y someterse a las sanciones que se señalaban en la ley. Los directores de La Vanguardia, desde el 18 de julio de 1936, quedaron pendientes de depuración. María Luz Morales, que había sido directora del rotativo desde el 7 de agosto de 1936, no fue una excepción y, aunque desempeñó el cargo durante algunos meses, fue denunciada y no se la eximió de que se le abriera expediente en 1940, un expediente que no se cerraría definitivamente hasta el 30 de septiembre de $1943^{25}$. La depuración a la que se vio sometida Morales tuvo, pues, consecuencias en su trabajo editorial, ya que tanto esos volúmenes para Araluce como muchas otras de sus traducciones de principios de los 40, aparecen sin su nombre o únicamente con sus iniciales, MLM.

Para la censura franquista cualquier vehículo de promoción de la cultura resultaba sumamente sospechoso, indistintamente de si el público al que iba destinado era infantil y juvenil o adulto:

En el caso de la literatura Infantil y Juvenil, este control ha sido, si cabe, más llamativo. Con la promoción y la censura de las obras infantiles se trasmiten únicamente las ideas afines al poder y, de este modo, se busca la pervivencia de los regímenes dictatoriales o totalitarios sobre la base de formar y adoctrinar a niños y jóvenes por medio de sus lecturas (Cerrillo 2016, 15).

A los criterios censores a los que se atendía en el caso de las publicaciones de adultos (ataca a la moral, a la religión, a sus ministros, al régimen y sus instituciones, etc.), se añadía en el caso de las publicaciones infantiles un nuevo valor: el de la ejemplaridad. Por ello no sorprende, como señala Sotomayor,

25 Agradezco a mi amigo y colega Manuel Llanas haberme cedido generosamente la documentación procedente de la Audiencia Provincial de Barcelona. 
que en los años 50 y 60 especialmente «las objeciones que aparecen en los informes se refieren casi siempre a cuestiones religiosas y morales, a un uso indebido del lenguaje, a la falta de respeto a los mayores o conducta inapropiada de los personajes» $(2016,19)$.

$\mathrm{Y}$, en efecto, las objeciones que determinadas censoras -curiosamente las obras adaptadas por Morales fueron juzgadas en su mayoría por mujeres- encontraron en algunos volúmenes de Araluce responden a esos criterios. Así, en Historias de Goethe, la censora encontró numerosos reparos y consideró que algunas expresiones podían ser amorales e incluso irreverentes: «Creemos que, en esta adaptación para niños, han de suprimirse las invocaciones religiosas y otras frases que en bocas de animales resultan irreverentes») (Expediente $\mathrm{n}^{\circ}$ 1040-53); o en el caso de las Trovas de otros tiempos, la censora apostilla: «En el cuento El castillo de irás y no volverás, el conjuro para obtener cosas maravillosas es «Dios y paloma», «Dios y león», «Dios y pulga», me parece que es irrespetuoso, ¿no podría cambiarse? [...] El cuento «La hija del conde Oliveros» es un asunto un poco peligroso, pues se trata de averiguar si una joven disfrazada de muchacho es chica o chico» (Expediente $\mathrm{n}^{\circ}$ 1041-53).

Pero el caso más espinoso se dio con las Historias de Schiller, pues la censora María Isabel Niño consideró que la adaptadora no había acertado en la selección de la segunda historia, Intrigas y amor, que superaba lo imaginable y no era apta para un público infantil. El Director General de Información dirigió un escrito a Araluce en el que conminaba a la editorial a suprimir la segunda historia y presentar de nuevo galeradas para conseguir el permiso de publicación y circulación. La carta lleva fecha de 20 de mayo 1953 y en la respuesta, datada el 3 de julio, Pedro Yúfera dice: «No veo posibilidad de complacerle, sin sufrir un fuerte quebranto económico, por lo que desisto ahora de editarlo» (Expediente n ${ }^{\circ}$ 2945-53). Y algo similar ocurrió con los Cuentos de Perrault, donde la censora María África Ibarra destacaba la inmoralidad de «Piel de Asno» y consideraba inadmisible su publicación.

Las Historias de Esquilo y las Historias de Sófocles, precisaron ser retocadas, pero las modificaciones fueron de menor importancia y María Luz Morales y la editorial se avinieron a ellas. En el primer caso, la censora, de nuevo María Isabel Niño, consideró que el contenido del libro podía atentar contra el ultracatolicismo del Régimen, e inducir a errores a los niños con poca formación. Es por ello por lo que se pidió una nota aclaratoria a la editorial. La nota explicativa, redactada por Morales, se añadió al prólogo de la reedición de 1956.

Algunos ajustes también tuvo que hacer Morales a las Historias de Sófocles, pues a la censora, una vez más, María Isabel Niño, le pareció poco adecuada la descripción de la muerte de la reina y los suicidios de Antígona y de la mujer de Hércules. Por lo que se conminó a la editorial a introducir las modificaciones indicadas y presentar nuevas galeradas. Morales se decidió por la supresión directa o el endulzamiento de algunos de los pasajes marcados por el lápiz rojo. 
En cuanto a los «Grandes hechos de los grandes hombres», los tres volúmenes preparados por Morales también tuvieron que pasar por censura. La primera petición de reeditar la obra que se hizo de la vida de Cervantes, en 1940, fue desestimada por considerar el Jefe de Lectorado inoportuna la aparición del nombre de la autora. Unos años más tarde, en 1948, se volvió a presentar la solicitud y la obra se pudo reeditar sin ningún problema porque ya no pesaba ningún cargo contra Morales. En la reedición de Vida y hechos de Alejandro Magno, de 1942, el censor consideró también que se podía publicar siempre y cuando no apareciera el nombre de la adaptadora. Por último, la reedición de la vida de Julio César, se produjo muy tardíamente, en 1951, y venía acompañada expresamente del Nihil Obstat del Obispado de Barcelona, firmado por el Dr. Cipriano Montserrat, canónigo. En esta ocasión se dictaminó que nada era censurable.

\section{UN FRACASADO INTENTO DE RECUPERACIÓN}

En 1997 el Grupo Anaya se propuso relanzar «Las obras maestras al alcance de los niños» de Araluce en una colección titulada «Biblioteca Araluce», «consecuencia de una ilusionada iniciativa de Emilio Pascual, director entonces de las colecciones infantiles del grupo» (García Padrino 2011, 33). El objetivo consistía en reeditar la colección con los mismos textos e ilustraciones originales, si bien con un nuevo formato. Los volúmenes medían 23 x $15 \mathrm{~cm}$ y la tapa, de cartoné, reproducía la imagen de la portada original:

\footnotetext{
Estas nuevas ediciones no eran una mera recuperación de tales volúmenes en un formato facsimilar, pues si bien se mantenían los textos sin modificaciones o correcciones, y, sobre todo, las magníficas ilustraciones de las primeras ediciones, la novedad residía ahora en una tipografía muy clara, una exquisita calidad en los componentes formales de la edición y un breve prólogo que intentaba situar cada adaptación y a sus autores e ilustradores en un contexto preciso (García Padrino 2011, 33).
}

Según indica Luis Alberto de Cuenca, el Grupo Anaya quiso «rentabilizar la nostalgia de los lectores de la colección Araluce, que fuimos legión en su momento» (2008) y recuperar el espíritu inicial de la colección, que no era otro que acercar los clásicos a los jóvenes. Los responsables de Anaya apuntaban como potencial público lector a los «niños y jóvenes que quieran conocer las grandes obras maestras, pero no tienen aún capacidad de acceder al original; a los adultos que en su niñez leyeron aquellos libros y, como Proust, andan a la 
búsqueda del tiempo perdido; y a todos los bibliófilos de buena voluntad» ( $E l$ País, 29/01/1998) ${ }^{26}$.

Pero el proyecto no tuvo éxito y solo publicaron algunos de los títulos, pues de los 93 volúmenes de que constaba la colección inicial, solo aparecieron una veintena, presentados por Luis Alberto de Cuenca y con prólogo de Jaime García Padrino: Historias de Shakespeare, Guillermo Tell, La Ilíada, La Odisea, La Eneida, Las mil y una noches, Fausto, Ramayana, Tradiciones Íberas, La leyenda de Sigfrido, Los caballeros de la tabla redonda, Historias de Calderón de la Barca, Historias de Dante, Historias de Lope de Vega, Leyendas de Oriente, El hombre que vendió su sombra, La canción de Rolando, Aventuras del Amadís de Gaula, Cuentos de la Alhambra y Los Lusíadas.

$\mathrm{Y}$ dos fueron las razones por las que se tuvo que retirar la colección del mercado. Por una parte, por el elevado precio de la edición, ya que la reproducción de las litografías originales y «la sobrecubierta del volumen con una ventanilla que dejaba ver la tapa reproducida del original» (García Padrino $2011,40)$ suponían una inversión que encarecía el coste del producto, y la rentabilidad no fue la que se esperaba. Por otra, el paso del tiempo. Es evidente el cambio que ha experimentado la mentalidad infantil y juvenil, especialmente en los últimos años, de modo que las explicaciones o justificaciones de los prólogos primigenios habían quedado completamente desfasadas, la estética de las ilustraciones no guardaba ya ninguna relación con los dibujos e imágenes que ilustran los libros infantiles y juveniles contemporáneos, y aquel lenguaje almibarado, con un estilo florido y afectado, con ecos de cuento antiguo, difícilmente podía conectar con el público de finales del XX y principios del XXI. Esos «queridos niños» o «cabecitas infantiles», con los que Morales apelaba directamente a sus lectores en los exordios, pertenecían ya a otra época. Para actualizar esos textos se hubiera precisado readaptar los textos de la gran adaptadora de Araluce: María Luz Morales. Pero no habría sido lo mismo.

\section{FUENTES}

Morales, María Luz. 1926. Julio César: Vida y hechos. 2. ${ }^{\text {a }}$ ed. Barcelona: Araluce.

Morales, María Luz. 1926. Miguel de Cervantes. Su vida gloriosa relatada a la juventud. Barcelona: Araluce.

Morales, María Luz. 1926. Vida y hechos de Alejandro Magno. 2. ed. Barcelona: Araluce. Morales, María Luz. 1928. Libros, mujeres, niños. Barcelona: Cámara Oficial del Libro. Morales, María Luz. 1939. Historias del romancero. Barcelona: Araluce.

Morales, María Luz. 1940. Historias de Lope de Vega. 3. ${ }^{a}$ ed. Barcelona: Araluce. Morales, María Luz. 1944. Las hazañas del Cid. Barcelona: Araluce.

26 «Anaya lanza una colección de libros clásicos juveniles». https://elpais.com/ diario/1998/01/29/cultura/886028408_850215.html. (Consultado: 20-20-2018). 


\section{BIBLIOGRAFÍA CITADA}

Abellán, Manuel L. 1980. Censura y creación literaria en España (1939-1976). Barcelona: Ediciones Península.

Albertí, Elisenda. 2015. Compromeses. Vuit dones catalanes excepcionals. Barcelona: Albertí Editor - Ajuntament de Barcelona.

Bravo-Villasante, Carmen. 1985. Historia de la literatura infantil española. 2. ${ }^{a}$ ed. Madrid: Editorial Escuela Española, S. A.

Bravo-Villasante, Carmen. 1989. Ensayos de literatura infantil. Murcia: Universidad de Murcia.

Cerrillo Torremocha, Pedro César. 2016. «Las censuras en la literatura infantil y juvenil». En Literatura y poder. Las censuras en la LIJ, ed. Ángel Luis Luján y César Sánchez Ortiz. Cuenca: Ediciones de la Universidad de Castilla-La Mancha.

Cuenca, Luis Alberto de. 2008. «Mi biblioteca de la colección Araluce». El Ciervo 68: 40-42.

Dalla-Corte Caballero, Gabriela. 2013. El archivo documental del americanismo catalán. Una historia centenaria para la Casa de América. Barcelona: Fundación Casa de América.

Diego Pérez, Carmen. 2011. «Un caso paradigmático de represión cultural: depuración de bibliotecas escolares en la provincia de Palencia durante la guerra civil española. Las bibliotecas del Patronato de Misiones Pedagógicas en la provincia de Palencia: dotación y depuración de sus fondos (2. ${ }^{\mathrm{a}}$ parte)». Represura 7. http://www.represura.es/ represura_7_febrero_2011_articulo1-parte2.html

Diego Pérez, Carmen y Montserrat González Fernández. 2008. «Gestación, dotación y expurgo de las bibliotecas escolares en España: 1869-1939». En Museos pedagógicos: la memoria recuperada, ed. Víctor Juan, 283-308 Huesca: Museo Pedagógico de Aragón.

Fulcarà Torroella, Maria Dolors. 2011. La Residència d'Estudiants de Catalunya (19211939). Barcelona: Publicacions i Edicions de la Universitat de Barcelona.

García Padrino, Jaime. 1999. «Del Ramayana a Trafalgar. Los clásicos al alcance de los niños». En Literatura y su didáctica, ed. Pedro C. Cerrillo y Jaime García Padrino, 139-159. Cuenca: Publicaciones de la Universidad de Castilla-La Mancha.

García Padrino, Jaime. 2011. «La colección Araluce: las obras maestras al alcance de los niños (1914-1955)». En Grands auteurs pour petits lecteurs: Adapter, traduire et illustrer les grands auteurs dans la littérature de jeunesse en langue espagnole, ed. Christine Pérès, 33-42. Lansman Editeur: Belgique.

García Padrino, Jaime. 2016. «Las ediciones infantiles en las corrientes estéticas de vanguardia (1915-1936)». EDETANIA 49: 29-43.

Guía de Editores. 1976. Madrid: Instituto Nacional del Libro Español.

Julio, Teresa. 2017. «María Luz Morales, traductora: estado de la cuestión y perspectivas de investigación». Confluenze. Rivista di Studi Iberoamericani IX, 2: 55-68.

Julio, Teresa. 2019. «María Luz Morales y la colección 'Las obras maestras al alcance de los niños' de Araluce ante la censura franquista». Boletín de la Real Academia Española 99 (320): 665-702.

Llanas, Manuel. 2005. L'edició a Catalunya: el segle XX (fins 1939). Barcelona: Gremi d'Editors de Catalunya.

Luzuriaga, Lorenzo. 1934. Bibliotecas escolares. 2. ${ }^{\text {a }}$ ed. Madrid: Publicaciones de la Revista de Pedagogía

Masoliver, Juan Ramón. 1983. «Los tiempos de Ángel Zúñiga». La Vanguardia, 15 de noviembre, p. 42. 
Muñoz Cáliz, Berta. 2006. Expedientes de la censura teatral franquista. Madrid: Fundación Universitaria Española.

Pascual, Emilio. 2010. «Un editor para la historia: Araluce y los libros». Diario de León, 12 de diciembre.

Rodrigo, Antonina. 2002. Mujeres para la Historia. La España silenciada del siglo XX. Barcelona: Carena.

Sánchez García, Raquel. 2001. «La edición de los libros infantiles y juveniles». En Historia de la edición en España (1836-1936), ed. Jesús A. Martínez Martín, 337-354. Madrid: Marcial Pons.

Servén Díez, Carmen. 2012. «María Luz Morales y la promoción de la literatura infantil». Álabe 5. http://doi.org/10.15645/Alabe.2012.5.3

Servén Díez, Carmen. 2016. «María Luz Morales (1889-1980): Entre la traducción y la adaptación». En Retratos de traductoras en la Edad de Plata, ed. Dolores Romero López, 177-198. Salamanca: Escolar y Mayo editores.

Sotomayor, M. ${ }^{a}$ Victoria. 2016. «Censuras de LIJ en España». En Literatura y poder: las censuras en la LIJ, ed. Ángel Luis Luján y César Sánchez Ortiz, 19-20. Cuenca: Ediciones de la Universidad de Castilla-La Mancha.

ANEJO

Listado de los títulos que María Luz Morales preparó para la editorial Araluce ${ }^{27}$ :

1. Historias de Shakespeare (n. ${ }^{\circ}$ 1). Contiene El mercader de Venecia, La fierecilla domada, La tempestad, Como gustéis, El sueño de una noche de verano, Cuento de invierno, Comedia de los errores y Las alegres comadres. Ilustraciones de José Segrelles.

2. Cuentos de Grimm (n. ${ }^{\circ}$ 6). Contiene El pescador y su mujer, Blancanieves y Encarnadarosa, La ondina del estanque, El fiel servidor, Nevadita y los enanillos, Juan Chiripero, Los músicos improvisados, El pájaro de oro y La verdadera princesa. Ilustraciones de Albert.

3. Los viajes de Gulliver a Liliput y Brodignac (n. ${ }^{\circ}$ 7). Ilustraciones de A. de La Portilla.

4. La Odisea (n. ${ }^{\circ}$ 12). Ilustraciones de José Segrelles.

5. La Ilíada o el sitio de Troya (n. $\left.{ }^{\circ} 13\right)$. Ilustraciones de José Segrelles.

6. La Gitanilla; El amante liberal (n. $\left.{ }^{\circ} 27\right)$. Ilustraciones de José Segrelles.

7. La Araucana (n. $\left.{ }^{\circ} 29\right)$. Ilustraciones de Albert.

8. Orlando furioso (n. ${ }^{\circ}$ 30). Ilustraciones de Albert.

9. Tradiciones íberas (n. ${ }^{\circ} 31$ ). Contiene La escala de la doncella, La virgen y la molinera, Las rosas de santa Casilda, El Cristo de la vega, La torre

27 Para la numeración de los volúmenes he seguido la lista de Luzuriaga (1927, 31-32). Como ya he indicado, uno de los inconvenientes de los tomitos es que no siempre llevan el año de edición y solo lucen, a veces durante varios años, el mismo Nihil Obstat de 1914. 
de don Rodrigo, San Jorge y el dragón, Las doncellas encantadas de la cueva de Vallderrós, El mal cazador, Jaun Zuria, Las ánimas y La torre de Hércules. Ilustraciones de José Segrelles ${ }^{28}$.

10. Hazañas del Cid Campeador (n. ${ }^{\circ}$ 32). Ilustraciones de José Segrelles.

11. Historias de Lope de Vega (n. ${ }^{\circ} 33$ ). Contiene La estrella de Sevilla, El mejor alcalde, el rey, y La dama boba. Ilustraciones de Albert.

12. Historias de Goethe (n. ${ }^{\circ}$ 39). Contiene Herman y Dorotea, Reineke el Astuto y Balada del conde desterrado. Ilustraciones de José Camins.

13. Historias de Ruiz de Alarcón (n. $\left.{ }^{\circ} 40\right)$. Contiene La verdad sospechosa, El tejedor de Segovia y Las paredes oyen. Ilustraciones de Albert.

14. Historias de Schiller (n. $\left.{ }^{\circ} 41\right)$. Contiene Los bandidos, Intrigas y amor, Los dos amigos y La conjuración de Fiesco. Ilustraciones de Ed. Gabelsberger.

15. Historias de Tirso de Molina (n. $\left.{ }^{\circ} 42\right)$. Contiene El vergonzoso en palacio, Don Gil de las calzas verdes y La prudencia en la mujer. Ilustraciones de José Camins.

16. Aventuras de Amadís de Gaula (n. $\left.{ }^{\circ} 43\right)$. Ilustraciones de Albert.

17. Las mil y una noches (n. $\left.{ }^{\circ} 44\right)$. Ilustraciones de Albert.

18. Historias de Eurípides (n. $\left.{ }^{\circ} 46\right)$. Contiene Alcestes, Hércules furioso, Ifigenia, El cíclope e Ión. Ilustraciones de José Camins.

19. Trovas de otros tiempos (n. $\left.{ }^{\circ} 47\right)$. Contiene El camino, El bufón del rey, El regalo del hada Mirbugis, Campanilla de Plata, El castillo de irás y no volverás, y La hija del conde Olivero. Ilustraciones de Albert.

20. La leyenda de Sigfrido (n. ${ }^{\circ}$ 48). Ilustraciones de Homs.

21. Historias de Esquilo (n. ${ }^{\circ} 49$ ). Contiene Prometeo encadenado, Los Siete contra Tebas, Los Persas, La Orestiada (Agamenón, Las Coéforas, Las Euménides), Las Suplicantes. Ilustraciones de Enrique Ochoa.

22. Aventuras de Gil Blas de Santillana (n. ${ }^{\circ}$ 51). Ilustraciones de José Segrelles.

23. Cuentos de Perrault (n. ${ }^{\circ}$ 53). Contiene Caperucita roja, La cenicienta, La bella durmiente, Piel de Asno, El gato con botas, Pulgarcito. Ilustraciones de Luis Álvarez.

24. Historias de Sófocles (n. ${ }^{\circ}$ 58). Contiene Áyax, Edipo Rey, Las Tarquinias y Filoctetes. Ilustraciones de Rapsomanikis.

25. Historias de Tennyson (n. ${ }^{\circ}$ 64). Contiene Gareth y Lynette, Nora, Enoch Arden, y Merlín y Bibiana. Ilustraciones de Enrique Ochoa.

26. Leyendas de Oriente (n. ${ }^{\circ}$ 65). Contiene La bella Zita, Savitri la fiel, De zapatero a rey, y La cacerola mágica. Ilustraciones de René.

${ }^{28}$ Este mismo volumen con idéntico contenido se publicó también con el título de Tradiciones hispanas. 
27. Historias del romancero ${ }^{29}$. Contiene romances moriscos (Las dos hermanas; Moriana y el moro galán); romances de la historia de España (Historia del último rey godo) y romances novelescos (La infantina encantada; La esposa del conde Sol; Calaynos, Roldán y la infanta Sevilla; Las princesas encantadas y los hermanos desleales). Ilustraciones de José Segrelles.

Fecha de recepción: 30 de mayo de 2018.

Fecha de aceptación: 5 de septiembre de 2018.

${ }^{29}$ En el momento en que Luzuriaga elabora el listado, que consta de 78 títulos, todavía no se había publicado este volumen sobre el romancero, de ahí que carezca de numeración. 